\title{
Identidade organizacional e os componentes do processo de identificação: uma proposta de integração
}

\section{Organizational indentify and the components of the identification process: an integration proposal}

\author{
Maria Elizabeth Rezende Fernandes ${ }^{1}$ \\ Antonio Luiz Marques ${ }^{2}$ \\ Alexandre de Pádua Carrieri ${ }^{3}$
}

\begin{abstract}
Resumo
Este artigo tem como objetivo analisar como se configuraram os componentes do processo de identificação em uma organização, cuja trajetória foi caracterizada por crescimento, crise e reestruturação. Buscando oferecer uma perspectiva qualitativa e integrada dos fenômenos "identificação" e "identidade organizacional", são aqui analisados os componentes cognitivo, afetivo e valorativo do processo de identificação propostos na teoria da identidade social e na teoria da categorização do self, com destaque para a identidade organizacional e para as similaridades no comportamento das pessoas, como bases do componente cognitivo. Essas abordagens foram integradas em um estudo de caso de uma empresa multinacional de tecnologia. Observou-se que na época de crescimento os empregados estabeleceram um estável senso de pertencimento com a empresa idealizada, amada e considerada prestigiosa, resultando na predominância de uma relação de dependência psicoemocional. Entretanto, a partir da crise e da reestruturação, ocorreu um movimento racional de desvinculação dos empregados com a empresa, reforçado pela alteração e instabilidade nos atributos e valores organizacionais. Isso foi fruto da perda do senso estável de pertencimento, da relação afetiva e da percepção de prestígio da empresa. Concluiu-se que organizações contemporâneas em processos de mudanças freqüentes e radicais têm perdido a conotação de espaços seguros com os quais as pessoas se identificariam, resultando numa relação mais racional de troca de interesses.
\end{abstract}

Palavras-chave: identificação; componentes do processo de identificação; identidade organizacional; identificação organizacional; mudança organizacional.

\begin{abstract}
This article aims to analyze how the components of the identification process are configured in a contemporary organization whose path was characterized by growth, crisis and restructuring. By seeking to offer a qualitative and integrated perspective of the identification and organizational identity phenomena, this paper analyzes the cognitive, affective and values components of the identification process. It was observed, into the case study of a multinational technology company that, during the time of growth, its employees established a stable sense of belonging with the idealized, loved and thought-to-be prestigious company, which led to the predominance of a psycho-emotional dependence relationship. Nevertheless, right after the period of crisis and restructuring, there was a rational movement that disconnected employees from the company which was intensified by the changes and instability that organizational attributes and values underwent. The conclusion reached was that contemporary organizations undergoing frequent and radical change processes have lost their connotation of being safe spaces people would identify themselves with.
\end{abstract}

Keywords: identification; identification process components; organizational identity; organizational identification; organizational change.

\footnotetext{
1 Psicóloga, mestre e Doutora em Administracão pela Universidade Federal de Minas Gerais - UFMG. Professora e Gestora na Fundacão Dom Cabral. Endereço: Fundação Dom Cabral - Avenida Princesa Diana 760, Alphaville Lagoa dos Ingleses - Nova Lima/Minas Gerais - Brasil - CEP: 34000.000. Email: bethf@fdc.org.br

2 Psicólogo, mestre e doutor em Administracão pela Aston University - United Kingdom. Professor e Pesquisador do Centro de Pós-Graduação e Pesquisas em Administração da Universidade Federal de Minas Gerais - CEPEAD/UFMG. Endereço: Universidade Federal de Minas Gerais - Departamento de Ciências Administrativas - Av. Antonio Carlos, 6627 - Edifício FACE, sala 4053 Campus Pampulha - Belo Horizonte/Minas Gerais - Brasil - CEP: $31270-901$. Email: marques@face.ufmg.br

3 Doutor em Administração pela Universidade Federal de Minas Gerais - UFMG. Professor Adjunto da UFMG; Coordenador do NEOS - Núcleo de Estudos Organizacionais e Sociedade do Departamento de Ciências Administrativas - UFMG. Av. Antonio Carlos, 6627 -

Edifício FACE, Sala 4071 Campus Pampulha - Belo Horizonte -Brasil - CEP: 31270-901. E-mail: alexandre@cepead.face.umg.br
}

Artigo submetido em novembro e aceito em dezembro de 2008 


\section{Introdução}

Os estudos sobre identificação na teoria organizacional ainda são incipientes, especialmente, quando se trata de focalizar a análise do processo de identificação das pessoas com as organizações, como um todo. Pratt (1998) argumenta que a opção tem sido por pesquisas instrumentais, desenvolvidas para comprovar a correlação positiva entre identificação e desempenho e a correlação negativa entre identificação e turnover. Assim, podese dizer que ainda existem muitas vias abertas de compreensão do fenômeno. Nesse sentido, Pratt (1998), bem como Gioia, Shultz e Corley (2000), entre alguns autores cujas contribuições têm se destacado, argumentam que, além da necessidade de serem realizadas pesquisas qualitativas sobre identificação, é preciso desenvolver análises integradoras que permitam um entendimento mais aprofundado no contexto das organizações.

Denominado "identificação organizacional” por Dutton, Dukerich e Harquail (1994), esse processo é entendido como a extensão pela qual as pessoas se entrelaçam psicologicamente com a organização e reconhecem, na sua identidade, a identidade organizacional. Em outras palavras, mediante a identificação ocorre a mediação entre a identidade pessoal e identidade organizacional. Para esta pesquisa, identidade organizacional é entendida como uma metáfora que exprime as percepções das pessoas acerca da essência de "quem somos nós como organização". A análise integrada dos estudos sobre "identidade" e "identificação" na teoria organizacional permite aprofundar a compreensão do significado que as pessoas atribuem às organizações, da forma como internalizam os valores e os atributos organizacionais, de como se categorizam como membros de uma mesma organização e da relevância das organizações na sua autodefinição e auto-estima.

Assim, contribuindo para o avanço do fenômeno nos estudos organizacionais, este artigo analisa a forma como se configura a identidade organizacional e os componentes do "processo de identificação" segundo a teoria da identidade social (TIS) e a teoria da categorização do self(TCS), propostas por Tajfel (1978; 1981), bem como Tajfel e Turner (1970; 1985): componente cognitivo - conhecimento proveniente da categorização, componente afetivo - vínculo emocional com o grupo e componente valorativo - conotação valorativa do grupo. Considerada base do processo cognitivo, a identidade organizacional é aqui tratada como base da categorização das pessoas com as organizações. Pratt (1998) auxilia essa compreensão ao argumentar que tal categorização ocorre desde que percebida a saliência da identidade da organização, ou seja, desde que sejam ressaltados os atributos da definidores da organização que passam a servir de referência para a definição do sujeito. Uma identidade organizacional é considerada saliente quando sua distintividade e relevância estabelecem, com clareza, os limites, as similaridades e as diferenças entre a organização e as demais.

Adotando uma perspectiva longitudinal, foi desenvolvido o estudo de caso de uma subsidiária de uma empresa multinacional de tecnologia, aqui tratada como NCB Brasil, no sentido de compreender a dinâmica do processo de identificação das pessoas com a empresa. De forma a facilitar o entendimento dos fatores que implicaram a configuração da "identificação organizacional" na NCB Brasil, ao longo dos anos, dois períodos foram destacados para análise: 1990 a 2000, período de crescimento da empresa, e 2000 em diante, período de enxugamento, caracterizado por instabilidade e rupturas na estratégia, na estrutura, na tecnologia, nos processos e no que se refere às pessoas. Foi necessário estabelecer esses marcos temporais para facilitar o resgate histórico das percepções sobre o processo de identificação, uma vez que o desenvolvimento da pesquisa ocorreu no segundo semestre de 2007.

Para estabelecer os parâmetros mínimos que fundamentam a análise dos componentes do processo de identificação em ambas as empresas, esse artigo está assim dividido:

- arcabouço teórico sobre identidade organizacional e identificação, com destaque para a teoria da identidade social e teoria de categorização do self; percurso metodológico ressaltando as categorias de análise adotadas;

- análise da dinâmica dos componentes do processo de identificação das pessoas com a NEC do Brasil durante o período de crescimento e a partir da reestruturação;

- discussão sobre as questões centrais dos componentes da identificação em contextos estáveis e instáveis e; 
- considerações finais.

\section{Identidade organizacional e identificação}

A metáfora "identidade organizacional" - relativamente nova na teoria das organizações -, que faz uma alusão ao self individual, surgiu a partir do artigo seminal de Albert e Whetten (1985), que a definiram como resultante de um conjunto de afirmativas sobre os atributos centrais, distintivos e duradouros da organização. Com o avanço dos estudos, foram incorporadas diferentes definições e abordagens, surgindo algumas dimensões antagônicas sobre o conceito, ora concebido numa perspectiva objetiva, como uma variável passível de ser manipulada, ora entendido de forma subjetiva, como as percepções dos sujeitos sobre "o que é a organização" (CUCHE, 1999). Este artigo assume a direção mais subjetiva do conceito, entendendo a identidade organizacional como a expressão das percepções das pessoas sobre o significado da organização. Além disso, as organizações são aqui entendidas como um tipo específico de categoria social quando expressam as características prototípicas abstraídas das pessoas consideradas seus membros (TAJFEL; TURNER, 1979; ASHFORTH; MAEL, 1989).

Apesar da variedade de conceitos e abordagens sobre identidade organizacional, Ravasi e Van Rekon (2003) argumentam que a maioria assume identidade organizacional como a combinação de processos cognitivos, esquemas interpretativos, entendimentos compartilhados e valores comuns percebidos pelas pessoas em relação a determinada organização. Os significados atribuídos às expressões culturais como símbolos, rituais, cerimônias, histórias, sinais e mitos, compartilhados na organização, delineiam a percepção das pessoas sobre a essência da organização, sobre sua identidade organizacional. Assim, o foco recai sobre como as pessoas coletivamente convergem ao encontrarem a resposta para a questão "quem somos nós como organização", construindo os sentidos sobre "o que é a organização".

Integrando identidade organizacional e imagem, Dutton e Dukerich (1991) fornecem mais uma perspectiva de análise argumentando que a identidade organizacional é uma das imagens que a organização possui. Ao estudarem, na década de 1990, o porto de Nova York, retrataram a diferença na percepção interna e externa sobre as imagens da organização: a percepção interna diz respeito àquilo que as pessoas "de dentro" acreditam ser os atributos centrais, distintivos e duradouros da organização; ou seja, a identidade organizacional. Quanto à percepção externa, esta diz respeito àquilo que os "de fora" pensam sobre a organização; ou seja, à imagem organizacional. Posteriormente Dutton, Dukerich e Harquail (1994) propuseram uma nova concepção, a imagem externa construída, fazendo referência à forma como as pessoas "de dentro" da organização acreditam que esta esteja sendo percebida pelos "de fora". Essa nova concepção torna-se relevante nos estudos sobre identificação, e, em especial, para efeito desta pesquisa, por salientar a percepção das pessoas sobre a valorização da identidade organizacional pelos "de fora", aspecto importante no entendimento do componente valorativo da identificação organizacional.

Nos últimos anos, vem crescendo o interesse dos estudiosos pelas perspectivas dinâmica e plural da identidade organizacional. Embora Albert e Whetten (1985), em seu artigo seminal, já tenham suscitado essas questões mesmo de forma não muito clara e até superficial -, ainda persistem muitas dúvidas sobre a mutabilidade da identidade organizacional. Para efeito desta pesquisa, assume-se uma perspectiva processual da identidade organizacional e, portanto, mutável, corroborando o que dizem alguns autores, como Elsbach e Kramer (1996); Gioia e Thomas (1996); Gioia, Shultz e Corley (2000); Corley e Gioia (2004), que argumentam ser aparente e ilusória a característica de durabilidade que foi conferida ao termo. Sua constituição é entendida como complexa, resultante das diferentes interpretações das pessoas sobre os aspectos simbólicos da organização, o que interferiria no seu processo de identificação com as organizações.

É recente o interesse dos teóricos organizacionais sobre o tema identificação organizacional, entendido como o processo pelo qual as pessoas integram na sua autodefinição a identidade organizacional. Entende-se que essa integração possa ocorrer tanto pelo reconhecimento de semelhança entre os valores da organização e os do sujeito, quanto pela mudança nos valores e crenças pessoais, para tornarem-se mais semelhantes aos da organização. Entretanto, não só a emulação e internalização de valores e crenças são os meios pelos quais os 
estudiosos sobre o tema (TAJFEL 1978; 1981; TAJFEL; TURNER, 1979; ASHFORTH; MAEL, 1989; PRATT 1998; KREINER, 1999; HOGG; TERRY, 2000; ASHFORTH, 2000) consideram que os sujeitos se identificam com as organizações. Várias outras formas são realçadas na teoria organizacional, tomando como base seus antecedentes, especialmente, a teoria da identidade social e a teoria da categorização do self, que sustentaram as análises do processo de identificação realizadas nesta pesquisa, permitindo o estudo mais aprofundado e integrado do fenômeno.

\section{A identificação na teoria da identidade social e na teoria da categorização do self}

As teorias da identidade social e da categorização do self influenciaram grande parte dos estudos sobre identificação organizacional, contribuindo para o entendimento das bases psicológicas dos processos de classificação adotados pelos sujeitos. Tajfel (1978), um dos fundadores da teoria da identidade social (TIS), defendia que parte do autoconceito do indivíduo seria derivada da sua identificação, do seu senso de pertencimento a determinado grupo ou grupos sociais. Ashforth e Mael (1989) foram os primeiros teóricos organizacionais a aplicarem as contribuições de Tajfel e Turner à teoria organizacional, o que vem sendo seguido desde então por outros autores. Nkomo e Cox Jr. (1999) ressaltam a relevância da TIS para uma melhor compreensão da perspectiva comportamental do sujeito como membro do grupo e da forma como este utiliza as categorias sociais para classificar a si mesmo e os demais.

Ashforth e Mael (1989) argumentaram que o sujeito, pela identificação, busca construir uma percepção de unidade e pertencimento a uma determinada agregação humana, como forma de responder parcialmente à questão “quem sou eu?". Isso significa que, pelo processo de identificação, o sujeito percebe-se como membro de determinado grupo ou categoria social, absorvendo para si as características do coletivo, o que afeta seu comportamento e suas atitudes. Esse senso de pertencimento está intimamente atrelado à percepção de limites do grupo, de diferenciação e distintividade. Os autores entendem que a percepção de fronteiras pode motivar o grupo "de dentro" a tornar-se mais homogêneo para diferenciar-se dos demais e se autoproteger. Van Knippenberg e Van Schie (2000) reforçam esse aspecto, ao salientarem que as pessoas seriam mais propensas a se identificar com grupos em que sentissem similaridade entre seus membros, seja pela delimitação das fronteiras do grupo, seja pela prototipificação dos comportamentos, o que significa a presença de comportamentos típicos entre os membros do grupo. No processo de identificação do sujeito com as várias categorias e grupos sociais, os autores da TIS e da TCS (TAJFEL, 1978; 1981; TAJFEL; TURNER, 1979; 1985) apontam três componentes: o cognitivo, o afetivo e o valorativo.

\section{Os componentes cognitivo, afetivo e valorativo do processo de identificação}

Para efeito desta pesquisa, os componentes explorados pela TIS e pela TCS são considerados relevantes para entender a configuração do processo de identificação das pessoas com as organizações. O componente cognitivo diz respeito à autocategorização e à autodefinição do sujeito. Isto é, ao estabelecer um senso de pertencimento a determinado grupo ou categoria social, a pessoa pode assumir seus protótipos e estereótipos, os quais expressam padrões e atributos que caracterizam e distinguem o grupo dos demais. Incluem-se aí as crenças, atitudes, sentimentos e o comportamento dos seus membros, maximizando as similaridades e as diferenças entre os grupos. A prototipificação consiste no processo pelo qual a pessoa se considera (ou é considerada) um típico exemplar de determinado grupo ou categoria. Entende-se por categoria as características prototípicas abstraídas dos membros de um determinado grupo (TAJFEL, 1981; TURNER et al, 1987; HOGG; TERRY, 2000; SILVA, 2002; BREWER; GARDNER, 2004).

O componente afetivo, incorporado ao componente cognitivo do processo de identificação, é retratado pelos sentimentos do sujeito em relação ao fato de pertencer a um determinado grupo social. Pela comparação com outros grupos, salientando suas similaridades, equivalências, intenções e comportamento, considera-se que o sujeito tenderia a se manter como membro do grupo que lhe propiciasse uma autodefinição positiva. Por outro lado, tenderia a desligar-se daquele grupo cujas características afetassem negativamente a sua autodefinição. Esse desligamento estaria condicionado, entretanto, à permeabilidade das fronteiras do grupo social. Por 
exemplo, grupos como raça e nacionalidade não seriam passíveis de serem abandonados pelo sujeito. Nesse caso, restaria à pessoa desenvolver mecanismos de aceitação, procurando adequar sua interpretação a eles (TAJFEL, 1981; HOGG; TERRY, 2000; READE, 2001).

O componente valorativo é vinculado à forma como, na percepção da pessoa, seu grupo social é valorizado pelos outros grupos. Essa percepção poderia ser positiva ou negativa, revelando tanto o valor e o prestígio do seu grupo social quanto a crítica dos demais grupos. O aspecto valorativo pode implicar uma forte motivação para os membros do grupo adotarem comportamentos geradores de uma percepção positiva (TAJFEL,1981; READE,2001). Nesse sentido, haveria uma maior tendência das pessoas a compartilhar valores, crenças, normas e regras dos grupos e das organizações percebidas como prestigiosas, o que poderia afetar de forma positiva a sua auto-estima e autodefinição (HOGG; ABRAMS, 1988; PRATT; FOREMAN, 2000; GIOIA; SHULTZ; CORLEY, 2000; ASHFORTH, 2001; CORLEY; GIOIA, 2004).

Van Dick (2001) argumenta que, embora todos os componentes sejam inter-relacionados, o componente cognitivo tende a ser o primeiro no processo de identificação do sujeito com determinado grupo. Somente a partir da percepção de pertencer, de ser membro de um determinado grupo social é que os outros componentes entrariam no jogo, não havendo, entretanto, uma relação seqüencial entre eles. Em seus trabalhos posteriores, Van Dick et al (2004) adiciona um quarto componente ao processo de identificação, o comportamental, que já havia sido mencionado nos trabalhos de Harquail (1998), referindo-se à participação do sujeito em ações relevantes para o grupo. Entretanto, esse componente não chega a ser explorado a ponto de vir a ser utilizado como uma das categorias de análise desta pesquisa. Van Dick (2001) considera que os membros de um determinado grupo sentir-se-iam motivados a contribuir com o sucesso do grupo porque isso aumentaria os sentimentos de orgulho e respeito em relação ao grupo e a si mesmos.

Finalizando, os antecedentes dos estudos sobre identificação na teoria organizacional - especialmente, os estudos da TIS e da TCS assumem que os indivíduos se comparam com outros pelo processo de identificação e que o nível da comparação é que determina o tipo de identificação: seja com o indivíduo, com o grupo ou com a organização. Ao sentir-se membro da organização, membro de determinados grupos nela inseridos, a pessoa pode se identificar cognitivamente com os respectivos protótipos e estereótipos. Pelo vínculo emocional, pode absorver para si os sentimentos relativos ao grupo ou à organização da qual se sinta membro. Sua auto-estima pode ser afetada pela forma como acredita que a organização é percebida pelos "de fora". A identificação pode ser entendida como um processo contínuo de construção, com probabilidade de maior intensidade em situações em que o sujeito enfrente vivências emocionais carregadas de emoção. Quando os sujeitos chegam a se definir, parcialmente, com os mesmos atributos da organização (ou seja, com a identidade organizacional), pode-se dizer que ocorreu um processo de identificação organizacional.

\section{Percurso metodológico}

A adoção do estudo de caso como estratégia de pesquisa justifica-se pela sua capacidade de lidar com uma ampla variedade de evidências, permitindo análises mais profundas sobre determinado fenômeno. Por ser a estratégia mais apropriada a estudos que se pretendam mais amplos e capazes de propiciar novas descobertas, oferece novas via de análise e de interpretação das ações, percepções, comportamentos e da interação das pessoas, retratando a realidade com profundidade em suas várias dimensões, paradoxos e conflitos (ANDRÉ; LUDKE, 1986; BRYMAN, 1992; YIN, 2005).

O desenvolvimento da pesquisa privilegiou a realização de análises documentais e entrevistas com 48 representantes dos diferentes níveis hierárquicos: diretores, gerentes e técnicos administrativos. Para uma maior compreensão sobre a configuração do processo de identificação ao longo do período, foram entrevistadas pessoas admitidas nos dois períodos anteriormente mencionados. Essas pessoas foram colocadas na condição de informantes, por serem consideradas mais aptas a fornecerem as informações sobre a evolução do fenômeno (RAVASI; VAN REKOM, 2003). A partir de alguns encontros com a diretoria de recursos humanos, foram selecionados os primeiros informantes, que, em seguida, indicaram outras pessoas a serem entrevistadas. 
Foram utilizadas as seguintes categorias de análise:

- contexto: estudo da evolução histórica da empresa, das principais mudanças e de seus impactos na organização, no sentido de estabelecer os marcos de análise do processo de identificação. A sua operacionalização ocorreu tanto pela análise de documentos (propiciando um resgate histórico), quanto pelas entrevistas.

- componente cognitivo do processo de identificação: compreende a análise da identidade organizacional, considerada a base do processo de identificação, desde que percebida como uma categoria social distinta, com a qual as pessoas estabeleceriam um senso de pertencimento estável. A operacionalização foi realizada por meio de um resgate histórico via análise de documentos e descrições dos entrevistados sobre os atributos considerados definidores da essência da organização ao longo dos anos, observando-se as manifestações sobre os aspectos simbólicos da cultura: valores, ritos, mitos, símbolos, fundamentos de políticas e práticas. Foram também analisadas as percepções das pessoas a respeito da presença de comportamentos compartilhados, reconhecidos como típicos do empregado da NCB Brasil, que lhes conferiam um senso de categorização.

- componente afetivo do processo de identificação: compreende as manifestações afetivas das pessoas sobre a organização, por meio da análise dos sentimentos e emoções envolvidos na sua relação com a NCB Brasil, nos dois períodos estabelecidos como marcos.

- componente valorativo do processo de identificação: vinculado à forma como, na percepção das pessoas, a organização era valorizada pelas pessoas "de fora", correspondendo à proposta de Dutton e Dukerich (1991) sobre "imagem externa construída".

Para o tratamento dos dados, foi utilizado o NVivo 7, considerado um dos softwares mais novos e completos para o tratamento de dados textuais, o que possibilitou classificar, triar e organizar os dados, de forma a localizar e comparar concomitantemente informações-chave. Por meio da utilização do software NVivo 7 foi possível ampliar o alcance das análises, de forma dinâmica, o que afetou positivamente a consistência dos resultados.

Os próximos tópicos destinam-se à análise do contexto da NCB Brasil e dos componentes do processo de identificação considerando o marco temporal estabelecido: período de crescimento que antecedeu a crise ocorrida no final dos anos de 1990 e início dos anos 2000; período de reestruturação até o ano de 2007.

\section{NCB Brasil: os componentes do processo de identificação durante o período de crescimento}

A NCB Brasil é considerada empresa pioneira em tecnologia, tendo sua matriz no Japão. Apresentando uma trajetória de crescimento e de conquistas, iniciou suas atividades no Brasil na década de 1960, reafirmando, ao longo dos anos, sua posição sólida e comprometida com o país. A década de 1980 foi uma época de mudanças e de avanços, quando a empresa alterou duas vezes seu controle acionário, para atender às exigências impostas pelo governo quanto à nacionalização de empresas. Apesar dessas mudanças, em apenas uma década, a percepção dos entrevistados foi de adaptação dos novos controladores aos valores, às diretrizes e aos processos de gestão da matriz japonesa. A década de 1990 é considerada áurea na evolução da empresa. Em 1997, o faturamento alcançou o patamar de US $\$ 1,300$ bilhão, com um quadro de pessoal de aproximadamente 3.500 empregados, conforme afirma um dos diretores. Entre 1987 e 1998, o faturamento chegou a ser multiplicado 30 vezes (BASIL; COOK, 1974, p.5).

Ao longo desse período, observa-se o estabelecimento de fortes vínculos emocionais e psicológicos das pessoas com a organização, o que foi revelado pela análise dos componentes do processo de identificação: cognitivo, afetivo e valorativo. Como o componente cognitivo diz respeito a estereótipos que expressam os padrões e os atributos compartilhados com a empresa, são aqui analisados a identidade organizacional e os comportamentos prototípicos das pessoas. De acordo com as entrevistas, na década de 1990, período que antecede à reestruturação, observa-se um compartilhamento dos atributos que caracterizaram a NCB Brasil. Embora, por duas vezes, a empresa tenha alterado sua composição acionária, a percepção é de que os atributos mantiveram- 
se estáveis ao longo do período: empresa de manufatura, tecnologia de ponta, pioneira, sólida e reconhecida pela qualidade dos seus produtos.

Essa estabilidade nos atributos organizacionais estava atrelada ao apoio da matriz e à trajetória de crescimento no Brasil. Um dos gestores comenta que "a NCB não era uma empresa que aqui se instalou para usufruir de forma oportunista do mercado. Criou raízes no Brasil, numa visão de longo prazo". A empresa é percebida como tendo exercido um importante papel no desenvolvimento do país; especialmente, pelo seu pioneirismo: "A NCB Brasil tinha como missão contribuir para o progresso da sociedade, fornecendo equipamentos e soluções de excelência". A qualidade dos produtos e a tecnologia de ponta eram fonte de orgulho: "A NCB Brasil era uma empresa conhecida por dar muito valor à qualidade dos seus produtos", "qualidade reconhecida mundialmente". "O orgulho da empresa era ter uma produção que se caracterizava pela excelência na qualidade, confiança no produto NCB, na marca NCB".

Os aspectos simbólicos que fundamentaram as políticas e práticas institucionalizadas revelam a percepção compartilhada de forte hierarquia, coletivismo, cooperação e paternalismo. O respeito rigoroso aos níveis hierárquicos delimitava os relacionamentos formais e o fluxo do processo decisório. Uma estrutura piramidal, departamentalizada organizava-se em feudos de poder, o que não impedia o senso de coletivismo, o foco nos objetivos da organização como um todo: "Todos vestiam a camisa, independente do feudo. Por exemplo, a entrega está atrasada, precisamos reverter, as pessoas se apoiavam e revertiam”. A cooperação denotava ser aspecto-chave no alcance dos objetivos da coletividade, o que facilitava o estabelecimento de laços afetivos entre as pessoas.

Percebida como uma empresa de gestão paternalista, a NCB Brasil caracterizava-se pela tolerância em relação a problemas de produtividade e a falhas no desempenho, pela ausência de cobrança individual e de punição, pela expectativa de dedicação irrestrita para atender à chefia. Percebe-se que as ineficiências eram encobertas e compensadas pelos esforços coletivos e pelo alto grau de dedicação: "As pessoas compensavam o despreparo com o empenho. O que não se conseguia fazer de dia compensava-se à noite", como afirma um dos gestores.

Valores como "respeito", "confiança", "honra aos compromissos", "ética" e "qualidade dos produtos" eram não só compartilhados, mas também admirados, conferindo aos empregados da NCB uma percepção de distinção no ambiente profissional e social. O respeito aos empregados tinha um estreito vínculo com a percepção de segurança, de estabilidade no emprego, de ambiente harmônico, relações amistosas entre as pessoas, cooperação, oportunidades de crescimento, senso de justiça e de um tratamento igualitário dispensado aos empregados: "Ambiente de respeito, as pessoas aceitavam os outros como eram, independente do cargo, do nível salarial. Todos eram iguais. Não havia uma discriminação". Existia a percepção de "valorização da prata da casa", que crescia na organização ocupando cargos mais altos na hierarquia. As relações estabeleciam-se na base da confiança, da transparência e da honestidade. Os acordos entre as pessoas estabeleciam-se sem a necessidade de formalização: "As pessoas confiavam no que era colocado; as coisas eram no 'fio do bigode', não tinha aquilo de perder a confiança. Sempre teve a transparência". Honrar os compromissos era um aspecto característico: "Uma vez consensado (sic), é compromisso".

Observa-se que a segurança no emprego, a confiança na empresa e a permanência das pessoas na NCB Brasil por muitos anos são fatores que reforçavam a construção de comportamentos compartilhados, caracterizados pela expressão "vestir a camisa". Vestir a camisa era um comportamento que distinguia os empregados da NCB Brasil em relação à concorrência, como revela um gestor: "A NCB tinha uma identidade, em termos de corpo de funcionários, diferente de muitas das empresas novas que vieram"; "A gente tinha um sentido de unidade muito grande. Parece que éramos nós e os outros da região". Esse comportamento caracterizava-se pela dedicação irrestrita e pela realização de sacrifícios em prol do coletivo, no sentido de abandonar projetos pessoais para dar prioridade à empresa: "Na $\mathrm{NCB}$, as pessoas faziam acontecer na garra e na coragem, em detrimento do patrimônio pessoal"; "Naquela época tinha uma coisa muito forte de vestir a camisa da empresa; uma coisa de compromisso, orgulho"; "O profissional daquela época era, em geral, a pessoa que vestia a camisa, faria tudo pela empresa, custasse o que custasse". O alto nível de dedicação expressava-se em longas jornadas de trabalho, compreendendo, muitas vezes, trabalhar durante as noites, finais de semana e feriados: 
"Muitos funcionários trabalhavam até a noite e, quando tinham que fazer uma proposta, dobravam. O nosso time fez isso várias vezes e ninguém reclamava. Queriam que a empresa ganhasse". "Você tinha horário para entrar e não tinha para sair. Isso fazia com que você tivesse uma ligação muito forte com a empresa. Não era uma relação estritamente profissional."

Fidelidade era outra característica esperada do empregado NCB Brasil: "Era valorizada a fidelidade das pessoas. Quem não agisse de acordo com o que era cultural, era traidor". Ser fiel à empresa significava, para os empregados, ser leal, agir de acordo com os valores da empresa, ser transparente e constante ao defender os interesses da empresa, ao honrar os compromissos firmados, o que era acompanhado, muitas vezes, por uma postura de submissão, reforçada pelo forte respeito à hierarquia. Tudo isso afetava a forma como as pessoas sentiam que a empresa era valorizada pelos "de fora", revelando forte carga emocional: "Acho que aquela empresa representava tudo; para mim representou muito".

Destacavam-se os sentimentos de orgulho, amor, prazer, satisfação, proteção e segurança. O sentimento de orgulho em pertencer à NCB Brasil relacionava-se à percepção de pioneirismo, excelência técnica, qualidade do produto e contribuição social: "Sentia parte da NCB. O sentimento era de um bom local para trabalhar, orgulho de pertencer ao grupo NCB". Em geral, as pessoas se orgulhavam da percebida solidez da empresa, da perspectiva de crescimento profissional. A percepção de estabilidade gerava segurança, o que se aliava ao sentimento de amor pela empresa e ao prazer em trabalhar nela.

Em relação à crença das pessoas sobre como a empresa era percebida pelos "de fora", o que corresponde à "imagem externa construída" (DUTTON et al, 1994) elas não estranhavam o fato de não ser uma empresa amplamente conhecida no mercado. Em geral, os empregados orgulhavam-se em apresentá-la àqueles que não a conheciam, enaltecendo suas qualidades. Quando conhecida - especialmente, pelos clientes -, a percepção é de que era uma empresa respeitada, reconhecida pela sua excelência técnica, pela qualidade dos seus produtos, pelo seu pioneirismo, pela seriedade diante dos compromissos assumidos:

Primeiro, era uma empresa forte, com um nome muito forte. Transmitia uma potência. Sempre teve a conotação de ser uma empresa japonesa, grande, alta tecnologia. Sentia orgulho de trabalhar numa empresa bem vista, de alta tecnologia. Não era assim muito conhecida. Quando perguntava "Você trabalha onde?", respondia que trabalhava na NCB. Não conheciam porque não era de consumo amplo. Quando tinha oportunidade de explicar a NCB para o leigo, dava um peso forte. As pessoas que já tinham ouvido falar te olhavam com um arregalar de olhos quando falava que trabalhava na $N C B$. Isso dava a impressão de que, por trabalhar na NCB, tínhamos algo especial. Para quem era funcionário, o ego ficava massageado.

Além do reconhecimento do mercado empresarial, os familiares de japoneses e descendentes orgulhavam-se do fato de os filhos trabalharem na NCB Brasil. Tudo isso conferia prestígio aos empregados que percebiam trabalhar numa empresa valorizada pelos "de fora" e objeto de desejo de muitos profissionais. Entretanto, a partir do final da década de 1990 e início dos anos 2000, essas percepções começaram a ser alteradas, em função da crise e posterior reestruturação deflagrada na empresa, o que tem afetado o processo de identificação das pessoas.

\section{Alterações nos componentes do processo de identificação a partir da reestruturação}

Com a privatização e a liberalização da economia para o mercado internacional, presenciou-se uma maior competição entre as empresas fornecedoras de tecnologia, anunciando-se tempos difíceis e de grandes riscos para o setor. Nesse período, a NCB Brasil alterou novamente seu controle acionário, voltando a ser uma subsidiária integral da corporação japonesa, perseguindo o desafio de trazer de volta a lucratividade e o crescimento sustentável então, abalado (BASIL; COOK, 1974). Entretanto, o que ocorreu foi um agravamento na situação da empresa, deflagrando uma crise sem precedentes, em função de estruturas de custos incompatíveis, perdas acarretadas por alterações no padrão tecnológico nacional, acirramento da competição por preços, aumento da concorrência, privatização no setor e estagnação do mercado comprador, entre outros 
aspectos. O faturamento caiu de US $\$ 1,300$ bilhão para $\mathrm{R} \$ 300$ milhões, aproximadamente, segundo um dos remanescentes. Esse cenário foi agravado pela maxivalorização do dólar - uma vez que a NCB Brasil "operava com um balanço muito alavancado em empréstimos dolarizados, diferentemente de outras empresas menos endividadas" - e pela retração do setor por causa da queda das ações das empresas virtuais.

Diante desse contexto, teve início um processo de reestruturação liderado por um grupo de pessoas interessadas em assegurar a sobrevivência da empresa, o que obteve, posteriormente, o apoio da matriz, afetando:

a) o modelo de negócios - a empresa passou a se posicionar como fornecedora de soluções em tecnologia por meio de parceiros estratégicos, no lugar de empresa produtora de tecnologia;

b) a estrutura - foi criada uma empresa de soluções, posteriormente integrada à NCB Brasil, além de alterações na forma como se estruturaram, a partir de 2000, as unidades da empresa;

c) a operação e processos - foram adotados processos para soluções em tecnologia, no lugar de processos para produção de equipamentos, demandando redesenho na cadeia de gestão da operação, direcionando-a para projetos;

d) perfil das pessoas - foram necessárias alterações nas competências e habilidades, agora, voltadas para soluções integradas de tecnologia;

e) quadro de pessoal - ondas de demissão a partir de 2000 tornaram a estrutura mais enxuta;

f) estrutura financeira - saneamento financeiro por parte da matriz e revisão nos contratos, mantendose somente os caracterizados por menor risco e maior rentabilidade.

Apesar de toda a instabilidade gerada ao longo da reestruturação, a NCB Brasil, já em 2003, dava sinais de retomada, elevando o faturamento de US\$84 milhões para em algo torno de US\$200 milhões. Em 2005, a empresa voltou a ser rentável e, em 2006, ocorreu a primeira remessa financeira para a matriz. Considerada um caso de referência, a reestruturação parece estar em fase de conclusão, e a expectativa é de crescimento nos próximos anos, no sentido de se atingir um patamar equivalente ao das maiores concorrentes no Brasil. Apesar dos sinais de renovação, os últimos anos revelaram-se traumáticos, impactando o processo de identificação das pessoas com a empresa, revelando uma alteração nos componentes cognitivo, afetivo e valorativo.

Em relação ao componente cognitivo, observa-se uma instabilidade na identidade organizacional, pela presença de novos atributos convivendo com os atributos do passado: empresa de serviços, integradora, com foco em soluções de tecnologia inovadoras e de valor agregado. Esses novos atributos, entretanto, ainda não estão claros para grande parte dos entrevistados, não sendo considerados distintivos e diferenciadores: "Quem é a NCB" de hoje? "Viramos o quê? Um escritório de revenda?" "O que significa soluções?"

O novo posicionamento da empresa vincula-se ao estabelecimento de alianças tecnológicas com empresas parceiras, deixando para trás a conotação de empresa manufatureira e pioneira em tecnologia, motivo de pesar para muitos: "Mudar dói. Dor de ver o passado destruído. Tem muita gente que não aceita a mudança". Os entrevistados atribuem ao pioneirismo e à qualidade tecnológica dos produtos, no passado, o "cartão de visitas" da empresa, o seu aval para o novo contexto: "Ainda quando se fala no nome NCB, o pessoal associa ao poderio de desenvolvimento de tecnologia própria". "Já não existe mais o orgulho do equipamento NCB, mas ele acaba sendo o cartão de visita, o passado do que somos hoje". Um técnico remanescente chega a considerála uma empresa "de tecnologia em potencial", por acreditar no retorno dos produtos NCB a qualquer momento.

Em relação aos aspectos simbólicos presentes na cultura, observa-se que não mais existe a percepção homogênea de antes, prevalecendo uma "miscigenação cultural". Nesse sentido, os entrevistados fazem referência à quebra da hegemonia dos aspectos da cultura japonesa, tão fortes no passado, destacando a presença atual de aspectos que atribuem à cultura americana: individualismo, competitividade, frieza nas relações, oportunismo e profissionalismo. Isso tem gerado insegurança e entristecido empregados antigos, que se sentem "machucados e muitas vezes desrespeitados". Um diretor observa que essas alterações têm incentivado uma separação entre vida profissional e pessoal, maior competição interna, além de uma valorização dos resultados individuais: 
A NCB Brasil antiga era muito familiar, as pessoas tinham muito tempo de casa e o gerente se comparava ao chefe da família que cuida dos filhos. O ambiente era gostoso, mas muito fechado. Hoje mudou muito, cliente é cliente, fornecedor é fornecedor, empresa é empresa e família é família. Procuramos desenvolver uma cultura em que existe a vida profissional, a empresa, os parceiros e os clientes. Hoje se valorizam mais os resultados individuais, o ambiente interno é muito mais competitivo do que no passado. Criou-se uma cultura de insegurança, diferente do passado, em que tínhamos um ambiente de grandes comemorações. As pessoas estão de cabeça baixa. Tudo isso gerou uma cultura tímida em relação ao passado.

Em relação aos valores do passado - respeito, confiança, honra aos compromissos, ética e qualidade dos produtos, de forma geral -, pode-se dizer que estão preservados. Entretanto, a percebida falta de respeito com as pessoas é acompanhada de uma maior frieza nas relações, bem como a sensação de descartabilidade por parte dos remanescentes, que se consideram preteridos em relação aos mais novos: "As pessoas que estão aqui há mais tempo deixaram de ter importância. Quem é novo e vem de fora tem mais importância que aqueles que estavam. Mas na hora do vamos ver quem resolve, são os mais antigos de empresa". Sentindo-se desvalorizados, os remanescentes procuram reduzir seu vínculo com a empresa: "Sinto-me cada vez mais distante dela por diferença de valores".

Ainda analisando o componente cognitivo, não mais se percebe a prototipificação dos comportamentos, como antes. Embora, em algumas áreas da empresa, procurem manter comportamentos típicos que caracterizavam o "corpo de funcionários distinto", hoje, percebe-se um "corpo de funcionários multifacetado". Enfraqueceu-se o comportamento "vestir a camisa" e foram assumidos novos comportamentos considerados "característicos da cultura americana": individualismo, oportunismo, competição interna e frieza nas relações.

Antigamente, vestia-se muito a camisa e se levava as coisas a ferro e fogo. Hoje é uma relação profissional. Não se vê a manutenção do time. As pessoas estão mais suscetíveis a troca de empresa. Acaba perdendo a identidade. Deixa de vestir a camisa, a relação é mais comercial. Perde um pouco daquela cara NCB. A NCB era assim, o estilo NCB. Passaram a surgir comportamentos mais oportunistas. Se no momento anterior era a coletividade, depois, começou a ter um comportamento diferente: eu é que tenho que me dar bem. Não me importo com o resto.

A percepção é de que o ambiente de trabalho tornou-se mais competitivo, não mais permitindo acomodação: "Acho que mudou muito, as pessoas são menos acomodadas"; "Agora parece que valorizam as pessoas que têm sede exagerada de crescimento pessoal, essa competitividade acentuada". A empresa tem absorvido novas práticas de gestão, admitido profissionais formados em outros contextos, incentivado o profissionalismo; ou seja, os resultados a qualquer custo, produtividade. Em geral, percebe-se uma pressão pelo autodesenvolvimento, sob pena de as pessoas tornarem-se obsoletas, descartáveis. Se, por um lado, esses movimentos têm implicado a diminuição da acomodação, por outro têm afetado os vínculos das pessoas com a empresa, sendo estabelecidas relações mais racionais, tornando mais superficiais os vínculos que integram empregado e empresa. As pessoas vêm se percebendo como "recursos" a serem mantidos somente se forem úteis:

Hoje, sente que, no geral, a relação é mais fria. Para mim, ficou na cabeça que você é um recurso da empresa. É útil enquanto produz algo de útil para a empresa. Não que esteja errado, da forma como é tratado é que gera desconforto.

Observando-se a diminuição da carga emocional que mantinha a "cola afetiva" do empregado com a NCB Brasil, são freqüentes sentimentos de decepção e de insatisfação convivendo com sentimentos de orgulho e de satisfação. A decepção e a insatisfação estão atreladas à quebra de confiança na empresa, às mudanças freqüentes, à percepção de descartabilidade dos empregados antigos, à falta de proteção e segurança. Isso tem acarretado o enfraquecimento dos sentimentos de amor e lealdade: "Perdeu, em relação ao passado, o sentimento de lealdade da empresa. As pessoas, hoje, sabem que a qualquer hora podem ser demitidas. Aquele nível de confiança já não existe tão forte". Em geral, as pessoas expressam "gostar da NCB" em substituição a "amar a NCB", como no passado. As relações entre as pessoas são percebidas como mais frias: "Não sinto o 
coração bater em nome da empresa, suar a camisa". Tudo isso tem afetado o processo de identificação, observando-se movimentos racionais das pessoas de desvinculação afetiva e psicológica em relação à organização.

Os sentimentos de orgulho e de satisfação expressam-se tanto pelo que foi a NCB Brasil no passado, quanto pela sua capacidade de retomada e superação: "Até hoje, tenho orgulho e satisfação porque é uma empresa que soube contornar e se reerguer pela força de vontade de fazer acontecer, cumprir o seu dever, até com debilidades. Isso eu admiro". A satisfação também se observa naquelas áreas em que ainda são mantidos o respeito mútuo e a valorização do empregado, e, por parte de quem é novo na empresa, ao fazerem referência ao ambiente de trabalho que consideram de respeito e favorável ao bom relacionamento entre as pessoas:

Uma coisa forte é o ambiente. Sempre ouvimos que é bom, sentimos. Acho que é o relacionamento entre as pessoas, a competitividade ainda é saudável. O ambiente de relacionamento e respeito. Isso tudo acaba criando um ambiente salutar de trabalho. As pessoas têm prazer, satisfação por estar numa empresa que ainda é reconhecida por ter tecnologia e nome em clientes do nosso segmento. $O$ respeito de mercado ainda motiva e o ambiente, o que faz com que as pessoas tenham prazer.

Em relação à forma como as pessoas percebem que a NCB Brasil é valorizada pelos "de fora", perdeu-se muito do prestígio de antes. A percepção é a de que a NCB Brasil deixou de ser competitiva no mercado brasileiro. Acredita-se que perdeu mercado, reconhecimento e prestígio por ter deixado a condição de manufatureira: "Os próprios clientes não se conformam. Ela era uma potência, dominava o mercado, e hoje em dia é o contrário. Talvez, essa mudança não tenha sido assimilada"; "diminuição da presença da NCB pela falta de produto próprio, selo NCB".

Para muitos, mesmo assim, sua imagem ainda se atrela à condição de manufatureira, de fornecedora de tecnologia própria: "Acho que ainda é reconhecida como um fornecedor de tecnologia. Acho que não mudou para soluções". Alguns entrevistados escutam comentários de que a empresa acabou, ou de que está sem rumo e mal administrada. Em meio a essas diferentes percepções, observa-se, de forma mais unânime, que as pessoas "de fora" ainda valorizam a NCB como uma empresa íntegra, que honra os compromissos, que tem um corpo qualificado de profissionais e cujos produtos têm qualidade, mesmo na condição de "integradora de soluções". Por fim, o período de reestruturação, percebido como bem-sucedido, vem sendo caracterizado por alterações no senso de pertencimento e pela diminuição da dependência psicológica das pessoas.

O próximo tópico analisa alguns aspectos considerados centrais para a compreensão da forma como se configuram os componentes do processo de identificação em contextos mais estáveis e em situações de reestruturação.

\section{Questões centrais dos componentes da identificação organizacional em contextos estáveis}

O compartilhamento de uma identidade organizacional sólida, estável e prestigiosa, aliado à prototipificação dos comportamentos, propiciou aos empregados da NCB Brasil, antes da reestruturação, uma segmentação cognitiva e um ordenamento do ambiente que resultaram em forte senso de pertencimento à empresa. Corroborando Pratt (1998), o reconhecimento das organizações como um tipo específico de categoria social estaria atrelado à saliência, ao realce da identidade organizacional e à expressão das características prototípicas abstraídas das pessoas consideradas seus membros. Essa seria, portanto, a base do processo de identificação, uma vez que permitira a categorização das pessoas como "membros" de um mesmo grupo social. Assim, a identidade organizacional compartilhada na NCB Brasil representou um componente significativo na forma como as pessoas se autodefiniam, decorrente dos significados por elas atribuídos à organização.

Ao sentirem-se "membros da NCB Brasil", as pessoas tornaram-se propensas a internalizar os valores coletivos, os significados e padrões culturais, reforçando a coesão, a similaridade nos comportamentos e a identificação com a organização. A coesão era reafirmada pelo compartilhamento dos atributos organizacionais e pela similaridade nos comportamentos que conferiam uma "cara NCB" ao empregado. Assim 
prototipificados, os comportamentos tornavam os empregados mais propensos a desenvolver uma percepção de distintividade, o que é ressaltado por Ashforth e Mael (1989). Depreende-se, portanto, que, pelo componente cognitivo do processo de identificação, as pessoas incorporam semelhantes visões de mundo, valores e códigos simbólicos, o que reforça a sua coesão na maneira de sentir, pensar, ser e agir, intensifica a percepção de distintividade e, por sua vez, promove a identificação organizacional.

A similaridade nos comportamentos das pessoas na NCB Brasil, expressa pela metáfora "vestir a camisa da empresa", implicava a dedicação irrestrita, sacrifícios pessoais em prol do coletivo e honrar os compromissos. O sacrifício pessoal em detrimento do coletivo denotava a falta de limites entre vida pessoal e profissional, pois sacrificar-se pela empresa significava o mesmo que trabalhar em beneficio próprio. Isso era reforçado pela segurança na empresa, percebida como um lugar para se aposentar. Depreende-se daí que a prototipificação dos comportamentos está atrelada à segurança de que a empresa seja um lugar estável na construção do senso de pertencimento. Isso reforça tanto a busca de coesão, no sentido de se manter a distintividade das pessoas, quanto a percepção de interdependência entre o destino das pessoas e o da organização.

Sentimentos positivos em relação à NCB Brasil, aliados à percepção, à valorização e ao prestígio por parte dos "de fora", também reforçaram a "cola" emocional e psicológica das pessoas com a organização. Esse aspecto corrobora os argumentos de Ashforth e Mael (1989) de que a percepção de prestígio atrela-se ao desejo das pessoas de aumentarem sua auto-estima reforçando a dependência psicológica com a organização. Entretanto, a partir da reestruturação, observam-se implicações nesses vínculos emocionais e psicológicos.

\section{Questões centrais dos componentes da identificação organizacional em contextos instávels}

O processo de reestruturação na NCB Brasil foi deflagrado por um grupo de profissionais muito identificado com a organização. Esse aspecto denota, por um lado, que a forte identificação organizacional favorece a coesão, o que poderia dificultar ações proativas de rupturas de padrões. Por outro lado, pode revelar um fator importante na reação das pessoas diante das ameaças e pressões do ambiente, considerando-se a predisposição a envolverem-se "de corpo e alma" no sentido de perpetuar a empresa, mesmo que para isso sejam necessárias rupturas. Isso se explica pelo fato de que, ao procurarem manter a integridade da empresa, as pessoas estariam buscando manter sua própria identidade.

Ao longo da reestruturação, observou-se na NCB Brasil, uma instabilidade na identidade organizacional, o que gerou ambivalências, pelo convívio de atributos antigos prestigiosos com novos atributos nem sempre aceitos ou mesmo compreendidos. Esses movimentos ambivalentes e até antagônicos podem ser considerados benéficos à adaptação e à sobrevivência das organizações em contextos turbulentos, como argumentam Gioia (2000) e Corley (2004). Por outro lado, há que se atentar para as conseqüências de tal instabilidade no processo de identificação das pessoas com a organização, resultando em vínculos mais frios e superficiais, que podem, no longo prazo, dificultar a mobilização das pessoas em prol do coletivo.

Aliada à instabilidade na identidade organizacional, a perda da prototipificação dos comportamentos que caracterizava as pessoas como um "corpo de funcionários distinto" afetou o senso de pertencimento a uma mesma categoria social distinta e prestigiosa. Considerando ser o processo cognitivo a base do processo de identificação, essas alterações foram acompanhadas por uma busca racional de desvinculação afetiva e psicológica por grande parte dos empregados antigos. Esse aspecto oferece novas vias de entendimento para os movimentos de desidentificação, considerados por Mannoni (1994) frutos do processo de tomada de consciência da identificação.

Há a percepção, por parte dos entrevistados, da ênfase no individualismo, de uma maior competitividade, da frieza nas relações e do senso de oportunismo, aspectos percebidos como antagônicos àqueles que no passado eram valorizados e mantinham as pessoas integradas à empresa: associativismo, dedicação irrestrita, lealdade e senso de coletivismo. Isso denota a importância de se observar, num processo de reestruturação, quais aspectos simbólicos da cultura que, se alterados, interferem na percepção de quebra no senso de continuidade da 
empresa. Uma percepção de ruptura histórica poderia, no limite, ameaçar a integridade da empresa, como ressaltam Gioia, Shultz e Corley (2000).

\section{Conclusão}

As análises propiciadas pela pesquisa na NCB Brasil sugerem que, ao mesmo tempo em que existiria um movimento das pessoas em busca de um senso de pertencimento mais estável, que lhes conferisse segurança, no atual contexto de turbulências e rupturas, as organizações estariam perdendo essa conotação de espaços seguros com os quais seriam estabelecidos fortes laços emocionais, em intensos processos de identificação.

Ao integrarmos as análises dos componentes do processo de identificação, ao longo dos dois períodos: de crescimento e de reestruturação, observam-se significativas diferenças. O período de crescimento é caracterizado por fortes vínculos emocionais e psicológicos das pessoas com a empresa, em processos de superidentificação. Os empregados se percebiam como membros de uma empresa idealizada que passou a fazer parte da sua autodefinição, afetando sua auto-estima. Esse processo, geralmente inconsciente, conferiu às pessoas uma confortável sensação de estabilidade, distintividade e completude, traduzida na atenção ao coletivo e na dedicação irrestrita à empresa. Com a crise vivenciada no final dos anos 1990 e início dos anos 2000, o senso de pertencimento e a identificação com a empresa foram aspectos relevantes no empenho das pessoas em encontrar alternativas para a crise. O processo de reestruturação então deflagrado contou com a adesão das pessoas predispostas a colocarem os objetivos coletivos acima dos interesses pessoais.

Entretanto, com o decorrer da reestruturação, alguns aspectos contribuíram para uma predominância do processo de desidentificação dos remanescentes e da construção de vínculos superficiais por parte dos admitidos a partir dos anos 2000, resultando no choque de realidade acerca da vulnerabilidade da empresa:

- esta perde a sua conotação idealizada, considerada a extensão da própria casa e, muitas vezes, personificada como mãe;

- as ondas de demissões provocam a quebra de confiança nos esperados vínculos duradouros;

- o ambiente se torna mais propício ao individualismo;

- há uma percepção de que o tratamento se tornara mais impessoal; e

- há falta de coesão quanto aos atributos definidores da organização e no que diz respeito aos comportamentos manifestados a partir da reestruturação.

Esses aspectos foram reforçados pela percepção de instabilidade na metáfora da identidade organizacional, acarretada pela coexistência de atributos antigos e novos na definição da NCB Brasil. Entretanto, mesmo gerando ambigüidades e conflitos em grande parte dos entrevistados, essa instabilidade revelou-se necessária para que houvesse a ruptura com o passado. Nesse sentido, as pessoas trouxeram, para o nível consciente, questionamentos sobre "Quem somos nós como organização?", o que parece ter favorecido o processo de mudança, mas também contribuído para a fragilização do senso de pertencimento.

Numa outra perspectiva de análise observa-se que, se por um lado, as empresas detentoras de intensos processos de identificação podem encontrar dificuldades para promoverem mudanças e rupturas, por outro lado, as intensas vinculações psicoemocionais podem motivar as pessoas a se empenharem na busca por alternativas e a aderirem às mudanças e rupturas julgadas necessárias e imprescindíveis. Se em contextos mais estáveis as organizações revelaram-se espaços propícios para que as pessoas buscassem um senso de pertencimento que lhes conferisse segurança, no atual contexto de turbulências e rupturas, as organizações parecem perder essa conotação. Menos susceptíveis a sacrifícios pessoais em prol do coletivo, as pessoas denotam maior propensão a enxergar as organizações de forma menos idealizada e a avaliar os ganhos e perdas que possam obter nestas permanecendo, numa clara relação de troca. Assim, receosas de se identificarem com uma só 
organização, as pessoas tendem a estabelecer uma vinculação mais parcial, superficial e emocionalmente controlada.

Por não mais encontrarem nas organizações espaços propícios à construção de relações afetivo-psicológicas duradouras que respondessem a sua busca por um senso de pertencimento mais estável, as pessoas passam a estabelecer outro tipo de vinculação psicoideológica - talvez, até mais idealizada -, traduzida na expressão profissional de mercado, presente no relato de muitos dos entrevistados. Assim, como que submetidas a outro aparelho de conversação, as pessoas tendem a idealizar e a reificar as características atribuídas ao profissional de mercado, divulgadas na mídia especializada, em livros e em treinamentos sobre gestão. Isso pode se revelar ainda mais ameaçador ao processo de despersonalização, pela falsa percepção de autonomia que encobre um novo tipo de dependência psicológica, sutil e alienadora. Essa possível forma de vinculação das pessoas a contextos competitivos pode constituir tema para futuras pesquisas.

Se essas questões parecem ser ameaçadoras para os sujeitos, a pesquisa revelou que a tendência de desidentificação das pessoas, bem como de estabelecimento de vínculos mais superficiais em contextos organizacionais mais instáveis, pode revelar-se igualmente ameaçadora para as organizações. Observou-se que a desidentificação gera uma desvinculação do sujeito em relação à organização, expressa em atitudes de desinteresse pelo coletivo, chegando à indiferença ou mesmo ao antagonismo entre objetivos e motivações pessoais e organizacionais, impondo novos desafios à gestão:

- obtenção de alto nível de dedicação e foco nos objetivos coletivos;

- engajamento das pessoas em situações de reestruturação;

- retenção de profissionais considerados estratégicos, quando assediados pela concorrência;

- construção de ambientes propícios ao estabelecimento de um diferencial competitivo, por meio das pessoas.

Ademais, não se pode confundir o aparente empenho das pessoas em cumprir o papel e as metas contratadas, com o processo de vinculação psicológica aqui referido. As consequiências dessa desidentificação e do estabelecimento dos vínculos mais superficiais, no longo prazo, merecem ser aprofundadas, uma vez que podem interferir na tão esperada diferenciação das organizações por meio das pessoas.

Encerrando este artigo, merecem destaque algumas das suas contribuições ao avanço da teoria da administração e dos estudos organizacionais, sem, entretanto, deixar de mencionar as limitações que condicionaram a pesquisa. A perspectiva teórico-metodológica aqui abordada inovou ao evidenciar a importância de uma compreensão integrada dos fenômenos "identidade organizacional" e "processo de identificação". Reforçou-se aqui a perspectiva, só mais recentemente estudada, da mudança da identidade organizacional entendida de forma processual, bem como da importância do estudo dos processos de identificação em ambientes organizacionais sujeitos a rupturas. Destacou-se o modo como as organizações, em processo de reestruturação, afetam as referências do sujeito no seu processo de autodefinição - ao transformar sua realidade subjetiva -, bem como as referências da própria organização, na construção da sua trajetória. Como base do componente cognitivo da identificação a identidade organizacional forneceu elementos para analisar se uma empresa pode ser considerada uma categoria social distinta, com a qual as pessoas estabeleceriam um senso de pertencimento. Além disso, foi aqui oferecida uma nova perspectiva para a análise qualitativa do processo de identificação das pessoas com as organizações como um todo.

Acredita-se que, ao elucidar algumas questões centrais sobre o processo de identificação, este artigo tenha contribuído para ampliar o debate e a compreensão sobre um tema relevante, cuja abordagem, no entanto, é ainda incipiente nos estudos organizacionais. Ao demonstrar como a identificação organizacional afeta a vida das pessoas e das organizações, espera-se estimular outras investigações que avancem a compreensão desse tema.

Por fim, faz-se necessário destacar algumas limitações que pautaram a realização dessa pesquisa. As análises aqui realizadas sustentaram-se nas reflexões dos entrevistados sobre experiências passadas, demandando, por 
parte destes, um resgate a posteriori de percepções longínquas. Esse distanciamento temporal dos fatos pode ter acarretado interferências nas impressões e emoções manifestadas, reforçando a idéia de que, aqui, foi realizada uma interpretação de interpretações. Ademais, ao se estabelecer marcos temporais, visando delimitar e facilitar o entendimento da configuração dos componentes da identificação com as organizações, pode se ter deixado escapar alguns aspectos relevantes no decorrer dos períodos pesquisados. Como a análise do processo de identificação restringiu-se à organização como um todo, não foi possível contemplar outros focos de identificação, tais como grupos de trabalho e liderança, o que permitiria maior aprofundamento na análise das implicações da reestruturação. 


\section{Referênclas}

ALBERT, Stuart; WHETTEN, David A. Organizational identity. Research in Organizational Behavior, v.7, p.263-296, 1985.

ASHFORTH, Blake E. Role transitions in organizational life: an identity-based perspective. Academy of Management Review, v.26, n.4, p.670-672, 2001.

KREINER, Glen E. How can you do it? Dirty work and the challenge of constructing a positive identity. Academy of Management Review, v.24, n.3, P.413-434, 1999.

MAEL, Fred A. Social identity theory and the organization. Academy of Management Review, v.14, n.1, p.20-39, 1989.

BASIL, Douglas Constantine; COOK, Curtis. The management of change. Maidenhead: McGraw-Hill, 1974.

BREWER, Marilyn B.; GARDNER, Wendi. Who is this "we"? Levels of collective identity and self representation. In: HATCH, Mary Jo; SCHULTZ, Majken (Ed.). Organizational identity: a reader. New York, NY: Oxford University Press, 2004. p.66-88.

BRYMAN, Alan. Research methods and organization studies. London: Routledge, 1992. v.20. (Contemporary Social Research Series).

CARRIERI, Alexandre de Pádua. O fim do "mundo Telemig": a transformação das significações culturais em uma empresa de telecomunicações. 2001. 326 f. Tese (Doutorado em Administração) - Centro de Pós-Graduação e Pesquisa em Administração, Universidade Federal de Minas Gerais, Belo Horizonte, 2001.

CORLEY, Kevin G.; GIOIA, Dennis A. Identity ambiguity and change in the wake of a corporate spin-off. Administrative Science Quarterly, V.49, p.173-208, 2004.

CUCHE, Denys. A noção de cultura em ciências sociais. Tradução: Viviane Ribeiro. Bauru: Edusc, 1999.

DUTTON, Jane E.; DUKERICH, Janet M. Keeping an eye on the mirror: image and identity in organizational adaptation. Academy of Management Journal, v.34, n.3, p.517-554, 1991

$\overline{263,1994}$ ; HARQUAIL. Organizational images and member identification. Administrative Science Quarterly, v.39, n.2, p.239-

ELSBACH, Kimberly D.; KRAMER, Roderick M. Members' responses to organizational identity threats: encountering and countering the Business Week rankings. Administrative Science Quarterly, v.41, n.3, p.442-476, 1996.

GIOIA, Dennis A.; SHULTZ; CORLEY. Organizational identity, image, and adaptive instability. Academy of Management Review, V.25, n.1, p.63-81, 2000.

; THOMAS, James B. Identity, image, and issue interpretation: sensemaking during strategic change in academia. Administrative Science Quarterly, v.41, n.3, p.370-403, 1996.

HARQUAIL, Celia V. Organizational identification and the "whole person": integrating affect, behavior, and cognition. In: WHETTEN, David A.; GODFREY, Paul C. (Ed.). Identity in organizations: building theory through conversations. Thousand Oaks, CA: Sage Publications, 1998. p.223-231. (Foundations for Organizational Science).

HERSZTERG, Carlos Alberto (ROITMAN, Ari). A desidentificação. In: MANNONI, M et al. As identificações na clínica e na teoria psicanalítica. Rio de Janeiro: Relume Dumará, 1994. p.171-196.

HOGG, Michael A.; ABRAMS, D. Social identifications: A social psychology of intergroup relations and group processes. London: Routledge, 1988.

; TERRY, Deborah J. Social identity and self-categorization processes in organizational contexts. Academy of Management Review, v.25, n.1, p.121-140, 2000.

LUDKE, Menga; ANDRÉ, Marli E. D. A. Pesquisa em educação: abordagens qualitativas. São Paulo: EPU, 1986. (Temas Básicos de Educação e Ensino).

NEC DO BRASIL. NEC: uma trajetória de confiança do país. São Paulo, 2004. Documento interno.

NKOMO, Stella M.; COX, Taylor, Jr. Diversidade e identidade nas organizações. In: CALDAS, Miguel P.; FACHIN, Roberto; FISCHER, Tânia (Org. ed. brasileira.). Handbook de estudos organizacionais: modelos de análise e novas questões em estudos organizacionais. 1.ed. São Paulo: Atlas, 1999. v.1, p.334-360. 
PRATT, Michael G. To be or not to be? Central questions in organizational identification. In: WHETTEN, David A.; GODFREY, Paul C. (Ed.). Identity in organizations: building theory through conversations. Thousand Oaks, CA: Sage Publications, 1998. p.171-207. (Foundations for Organizational Science).

FOREMAN, Peter O. The beauty of and barries to organizational theories of identity. Academy of Management Review, V.25, n.1, p.141-152, 2000.

RAVASI, David; VAN REKOM, Johan. Key issues in organizational identity and identification theory. Corporate Reputation Review, v.6, n.2, p.118-132, 2003

READE, Carol. Dual identification in multinational corporations: local managers and their psychological attachment to the subsidiary versus the global organization. International Journal of Human Resource Management, v.12, n.3, p.405-424, 2001.

SILVA, Georgina A. Vieira da. Organizações flexíveis: identidades elásticas? A reconstrução da identidade social em processos de terceirização. 2002. 193 f. Tese (Doutorado em Psicologia) - Instituto de Psicologia, Universidade de São Paulo, São Paulo, 2002.

TAJFEL, Henri (Ed.). Differentiation between social groups: studies in the social psychology of intergroup relations. London: Academic Press, 1978. p.61-76.

. Human groups and social categories. Cambridge: Cambridge University Press, 1981.

; TURNER, J. C. An integrative theory of intergroup conflict. In: WORCHEL, Steven; AUSTIN, William G. (Ed.). The social psychology of intergroup relations. Monterey, CA: Brooks/Cole, 1979. p.33-47.

The social identity theory of intergroup behavior. In: WORCHEL, Steven; AUSTIN, William G. (Ed.). Psychology of intergroup relations. 2.ed. Chicago: Nelson-Hall, 1985. p.7-24.

TURNER, J. C. et al. Rediscovering the social group: a self-categorization theory. Oxford: Basil Black-Well, 1987.

VAN DICK, Rolf. Identification in organizational contexts: linking theory and research from social and organizational psychology. International Journal of Management Reviews, v.3, n.4, p.265-283, 2001.

et al. The utility of a broader conceptualization of organizational identification: which aspects really matter? Journal of Occupational and Organizational Psychology, v.77, n.2, p.171-191, 2004

VAN KNIPPENBERG, Daan; VAN SCHIE, Els C. M. Foci and correlates of organizational identification. Journal of Occupational and Organizational Psychology, V.73, p.137-147, 2000.

YIN, Robert K. Estudo de caso: planejamento e métodos. Tradução: Daniel Grassi. 3.ed. Porto Alegre: Bookman, 2005. 